DE

M E D I C I N A

T R O P I C A L

$\mathrm{DE}$

SÃO PAULO

JOURNAL OF THE SÃO PAULO INSTITUTE OF TROPICAL MEDICINE

'Universidade Federal Rural do Semi-Árido, Hospital Veterinário Jerônimo Dix-Huit Rosado Maia, Mossoró, Rio Grande do Norte, Brazil

2Universidade Federal do Espírito Santo, Departamento de Medicina Social, Vitória, Espírito Santo, Brazil

Correspondence to: João Marcelo Azevedo de Paula Antunes Universidade Federal Rural do Semi-Árido Hospital Veterinário Jerônimo Dix-Huit Rosado, Av. Francisco Mota, 572, Costa e Silva, CEP 59625-900, Mossoró, RN, Brazil Tel: $+55843317-8310$

E-mail: joao.antunes@ufersa.edu.br

Received: 17 May 2019

Accepted: 5 August 2019

\section{Armadillos and leprosy: from infection to biological model}

\author{
Ilanna Vanessa Pristo de Medeiros Oliveira $^{\left({ }^{1} \text {, }\right.}$, Patrícia Duarte Deps ${ }^{(1)}$, \\ João Marcelo Azevedo de Paula Antunes ${ }^{(1)}$
}

\section{ABSTRACT}

Mycobacterium leprae is the primary causative agent of Hansen's disease or leprosy. Besides human beings, natural infection has been described in animals such as mangabey monkeys and armadillos. Leprosy is considered a global health problem and its complete pathogenesis is still unknown. As M. leprae does not grow in artificial media, armadillos have become the primary experimental model for leprosy, mimicking human disease including involvement of the peripheral nervous system. Leprosy transmission occurs through continuous and close contact of susceptible people with untreated infected people. However, unknown leprosy contact has been reported in leprosy-affected people, and contact with armadillos is a risk factor for leprosy. In the USA, leprosy is considered a zoonosis and this classification has recently been accepted in Brazil. This review presents information regarding the role of wild armadillos as a source of $M$. leprae for human infections, as well as the pathogenesis of leprosy.

KEYWORDS: Mycobacterium leprae. Dasypus novemcinctus. Euphractus sexcinctus. Hansen's disease. Leprosy.

\section{INTRODUCTION}

Leprosy is a chronic infectious disease caused by Mycobacterium leprae ${ }^{1}$ (Hansen's bacillus) and Mycobacterium lepromatosis ${ }^{2}$. The most common causative agent is $M$. leprae, an obligate intracellular pathogen of high infectivity and low pathogenicity. Recent research has shown variation in the genetic diversity of isolates from different continents, ethnic groups and host species ${ }^{3}$. In addition, its clinical manifestation is broad, with widely divergent immunological characteristics ${ }^{4}$, hindering the diagnosis.

A susceptible individual, once infected, generally exhibits an incubation period of three to seven years until symptoms and physical signs of the disease are observed. Men are more affected than women, with signs in men usually starting in the second and third decade of life. Children may be affected mainly in areas where leprosy has high endemicity ${ }^{5}$. The disease mainly affects the skin and peripheral nerves, but the multibacillary form often affects the eyes, oro-nasal mucosa, testicles, bones and other tissues ${ }^{6}$.

The highest incidences are found in tropical and subtropical climates and, to date, it is a significant public health problem, especially in Asia, Africa and South America $^{7}$. In 2017, 210,973 new cases of leprosy were reported by 147 countries or territories ${ }^{8}$.

Transmission of Hansen's disease generally occurs via droplets of secretions released from the oro-nasal cavity, through sneezing or coughing, from symptomatic 
or asymptomatic individuals with mycobacteria ${ }^{9}$. However, the exact mechanism of transmission of the disease in the population is still debated, especially regarding environmental sources of M. leprae and their role in human disease, as well as the classification of Hansen's disease as a zoonosis ${ }^{10,11}$. Moreover, suspicions of the existence of infected animals such as armadillos and primates acting as environmental reservoirs and sources of $M$. leprae have increased ${ }^{12}$. Issues related to individual immunological susceptibility in the pathogenesis of infections by M. leprae in humans and animals and the new causative agent identified the $M$. lepromatosis, still need to be clarified. The recently reported presence of M. leprae and $M$ lepromatosis in red squirrels (Sciurus vulgaris) in the British Islands does not appear to pose an increased risk to human health ${ }^{13}$. Difficulties inherent to the study of Hansen's disease include the shortage of bacillus for studies, the fact that the bacillus does not grow in artificial media and experimental animal models are rare 4 .

The objective of this manuscript is to review published studies on M. leprae research in wild armadillos combining results from different databases and summarizing current evidence on specific issues. We attempted to resolve conflicts between studies and to determine whether results could be summarized when individual studies were inconclusive or contradictory. We searched three electronic databases (PubMed, Scielo, and Web of Sicence) for observational and experimental studies published in indexed journals. Search terms included the keywords "armadillo", "Mycobacterium leprae", "Leprosy" and "Hansen disease". We included manuscripts written in English/Portuguese and published between 1960 and 2018. This search strategy identified (after de-duplication) 58 articles describing leprosy in armadillos.

\section{Armadillos as a model for Hansen's disease}

To circumvent the problem that the bacillus $M$. leprae cannot be cultivated in vitro, Shepard in $1960^{14}$ established an animal model consisting of bacilli multiplication in the mouse pad. In 1971, Kirchheimer and Storrs ${ }^{15}$ achieved the spread of $M$. leprae in nine-banded armadillos (Dasypus novemcinctus) in captivity, and soon after in the seven-banded armadillo (Dasypus hybridus) ${ }^{16}$. Currently, D. novemcinctus is considered the most appropriate armadillo species for leprosy research ${ }^{4,17}$.

\section{Natural infection of $M$. leprae occurring in wild armadillos}

Some primate species (Pan troglodytes, Cercocebus atys and Macaca fascicularis $)^{18}$ and armadillos ${ }^{19}$ are susceptible to M. leprae infection and are naturally infected. In North America, where armadillos are considered a reservoir of Hansen's bacillus ${ }^{20}$, strains of M. leprae from armadillos have been found in almost two-thirds of the autochthonous human leprosy cases in Southern USA ${ }^{21}$.

Table 1 shows published studies on the natural infection of M. leprae in wild armadillos. These studies strengthen the hypothesis of armadillos as a zoonotic source of M. leprae, and demonstrate that armadillos and humans develop a

Table 1 - Studies on M. leprae infection naturally occurring in wild armadillos

\begin{tabular}{|c|c|c|c|}
\hline Authors & Year & Location & Armadillo species \\
\hline Walsh et al. & $1975^{23}$ & Louisiana/ USA & Dasypus novemcinctus \\
\hline Stallknecht et al. & $1987^{57}$ & Louisiana/ USA & Dasypus novemcinctus \\
\hline Truman et al. & $1990^{58}$ & Texas and Louisiana/ USA & Dasypus novemcinctus \\
\hline Zumarraga et al. & $2001^{33}$ & Corrientes/ Argentina & Dasypus novemcinctus \\
\hline Deps et al & $2002^{29}$ & Espirito Santo/ Brazil & Dasypus novemcinctus \\
\hline Deps et al. & $2007^{30}$ & Espirito Santo/ Brazil & Dasypus novemcinctus \\
\hline Deps et al. & $2008^{10}$ & Espirito Santo/ Brazil & Dasypus novemcinctus \\
\hline Cardona-Castro et al. & $2009^{26}$ & Barbosa/ Colombia & Dasypus novemcinctus \\
\hline Antunes et al. & $2009^{31}$ & Espirito Santo / Brazil & Dasypus novemcinctus \\
\hline Truman et al. & $2011^{20}$ & $\begin{array}{c}\text { Arkansas, Alabama, Louisiana, } \\
\text { Mississippi, and Texas / USA }\end{array}$ & Dasypus novemcinctus \\
\hline Frota et al. & $2012^{32}$ & Ceara / Brazil & $\begin{array}{c}\text { Euphractus sexcinctus and } \\
\text { D. novemcinctus }\end{array}$ \\
\hline Sharma et al. & $2015^{41}$ & $\begin{array}{c}\text { Mississippi, Alabama, Georgia, } \\
\text { and Florida / USA }\end{array}$ & Dasypus novemcinctus \\
\hline da Silva et al. & $2018^{43}$ & Para / Brazil & Dasypus novemcinctus \\
\hline
\end{tabular}


similar clinical picture (skin ulcers ${ }^{17}$ and infection of the peripheral nerves ${ }^{22}$ ) of Hansen's disease ${ }^{6}$.

In 1975, Walsh et al. ${ }^{23}$ reported that free-living armadillos from Louisiana harbored natural M. leprae infection and further investigations have shown the spread of the bacterium in Southern US armadillo population ${ }^{23,24}$, Mexico $^{25}$, Colombia ${ }^{26,27}$, Brazil ${ }^{10,28-32}$ and Argentina ${ }^{33}$.

In 2002, Deps et al..$^{29}$ reported M. leprae infection in wild armadillos in Brazil using the Polymerase Chain Reaction (PCR), and afterwards by the lateral flow serological technique (ML Flow test ${ }^{30}$ ). These studies established that, in Southeast Brazil, armadillos can be considered a natural reservoir of M. leprae. An epidemiological approach in the same area revealed that direct exposure through hunting or consumption of armadillo meat was associated with two-fold higher chance of leprosy in humans ${ }^{34,35}$. These epidemiological studies in the USA and Brazil were supported by reports showing M. leprae infection occurring naturally in wild armadillos ${ }^{20,29,30,32}$. In addition, a standard single genotype (SNP type) for the strain of M. leprae in armadillos and patients from the USA was reported ${ }^{20}$.

\section{Armadillos as a source of $M$. leprae for humans}

The possibility of an active participation of armadillos in the transmission of human leprosy is reinforced in areas with infected armadillos, where people affected by leprosy report no previous contact with infected individuals ${ }^{36-38}$. An association between leprosy and contact with armadillos has been reported mainly in people who handled or ate armadillos ${ }^{34-36,38-40}$. A case report from the USA describes a patient without travel history to endemic countries or contact with people infected with M. leprae, but who reported contact with armadillos ${ }^{38}$.

The interaction between armadillos and M. leprae will lead to the development of a range of natural resistance among animals in the same locality, which will be strongly influenced by individual and genetic factors. Susceptible armadillo species from South America, such as D. hybridus and E. sexcinctus, do not exist in North America $^{32,41}$. Regarding the origin of leprosy in Brazil and the Americas, the dominant Single Nucleotide Polymorphism (SNP) types found in Brazil are SNP type 3, the same subtype found in Europe that was transported to the New World by European explorers, and SNP type 4 from West Africa, that was transported during the slave $\operatorname{trade}^{42}$. This supports the belief that animal infections in the Americas originated from humans who migrated from the places of origin of M. leprae (Europe and West Africa $)^{42}$, as confirmed by Frota et al $^{32}$ who found the SNP type 3 in armadillos from Northeast Brazil, the same genotype found in naturally infected armadillos in Louisiana, $\mathrm{USA}^{20}$.

M. leprae infection occurring in wild armadillos is an emerging infection in Southern USA. In most of the infected animals, the agent is a single predominant $M$. leprae strain type, associated with the probable zoonotic transmission of leprosy ${ }^{20}$. M. leprae genotypes 3I-2-v1 and 3I-2-v15 were detected in armadillos, and $42.3 \%$ (22/52) of people affected by leprosy were infected with one of these two strains ${ }^{41}$.

da Silva et $a l .{ }^{43}$ identified a significant relationship between armadillo meat consumption and transmission of $M$. leprae, probably indicating transmission through capture and maintenance of armadillos in captivity before consumption ${ }^{11}$. On the other hand, Schmitt et al. ${ }^{44}$ found no association between consumption of armadillo meat and the disease.

In Brazil, two species of armadillos, E. sexcinctus and $D$. novemcinctus, have been identified as natural carriers of M. leprae $e^{10,29,30,32,39}$. Subsequently, Frota et $_{\text {al. }}{ }^{32}$ sequenced the genotype of M. leprae from armadillos in Northeastern Brazil, finding the SNP type 3, the same identified in armadillos from Louisiana ${ }^{20}$ and in people affected by leprosy in Brazil ${ }^{45}$. Besides Brazil and the USA, direct contact with armadillos in Mexico and Colombia has been implicated in the zoonotic transmission of Hansen's disease ${ }^{25,26}$. It is therefore highlighted that the most significant exposure to environmental M. leprae is through direct contact with armadillos, with potential zoonotic cases being of public health concern ${ }^{20,43}$.

Descriptions of infection patterns in wild armadillos remain scarce, and transmission mechanisms are unknown ${ }^{46}$. M. leprae infection in armadillos seems to spread naturally, probably increasing the likelihood of human infection ${ }^{25,40}$. The transmission of $M$. leprae to humans presupposes contact between infected armadillos and susceptible individuals. There is an association between contact with $D$. novemcinctus and the development of leprosy in people living near the armadillo's natural habitat ${ }^{35,36,47}$, suggesting the potential for these species to spread M. leprae ${ }^{18}$ into the environment.

\section{Armadillos as animal models for the study of leprosy}

Microbiological studies using the etiological agents are essential to understand any infectious disease. Because M. leprae and M. lepromatosis do not grow in artificial media, studies on leprosy are limited to sampling infected human tissues ${ }^{48}$. However, researchers have to deal with ethical limitations, difficulties in accessing infected tissue, and samples that are not suitable for molecular analysis ${ }^{49}$. The other option is to use animals as a source of M. leprae ${ }^{50}$.

An ideal animal model should become infected 
without immunosuppression and develop the disease like humans, with similar bacteriological and histopathological features ${ }^{51}$. Monkeys, chimpanzees, pigs, dogs and bats have unsuccessfully been explored as animal models for leprosy ${ }^{15}$. Animals with body temperatures below $37^{\circ} \mathrm{C}$ seem to be more prone to M. leprae infection so that susceptible animal hosts are limited ${ }^{50}$.

Shepard ${ }^{14}$ introduced the mice plantar foot pad cushion model, but replication of the bacilli is much more emphatic in the footpad and there is no nerve involvement. Subsequently, naturally acquired and experimental M. leprae infection was described in chimpanzees (Pan troglodytes), mangabey monkeys (Cercocebus atys), cynomolgus monkeys (Macaca fascicularis) ${ }^{19}$ and armadillos (D. novemcinctus $)^{26}$. In 1971, the armadillo was established as the best experimental model of $M$. leprae infection due to its ability to mimic human disease and produce a good number of bacilli ${ }^{15}$.

Infection in these animals manifests systemically, especially in reticuloendothelial tissues ${ }^{52}$, with intermittent bacteremia in all organs; extremities of the body with lower temperatures are more affected ${ }^{53}$. Experiments infecting lower body temperature $\left(32-35^{\circ} \mathrm{C}\right)$ nine-banded armadillos using various routes of infection (intravenous, intradermal, percutaneous, inhalation, intraperitoneal) established that this species and the intravenous route provide the most useful animal model ${ }^{17}$ in terms of a good number of mycobacteria in the first 18 months of infection ${ }^{6,54}$. However, even following this infection protocol, $15-20 \%$ of animals do not develop the disease ${ }^{50}$. In naturally infected animals, about 5\% develop clinical features of leprosy ${ }^{10}$ and $90 \%$ of the animals that show signs of systemic dissemination die from leprosy ${ }^{55}$. The most common clinical signs observed are typical plantar ulceration (Figure 1), and skin wear around the eyes, nose, feet, and parts of the body subject to friction (Figure 2). In the laboratory, foot ulcers increase as the infection progresses due to decreased extremity sensitivity ${ }^{17}$.

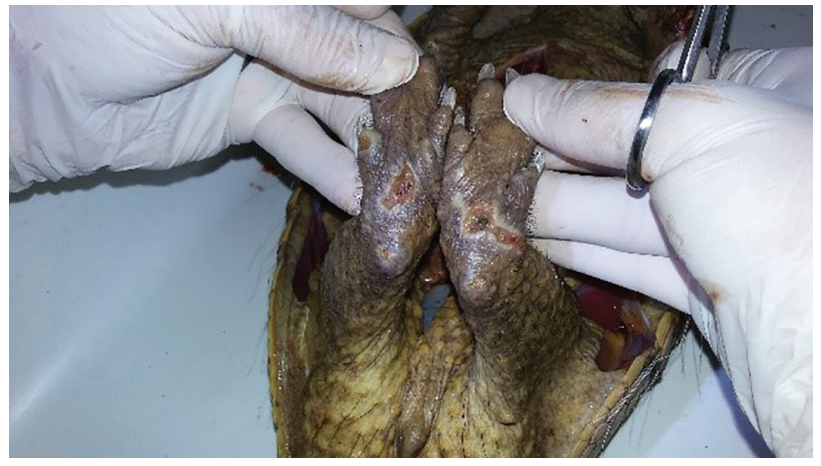

Figure 1 - Plantar injury in a naturally infected E. sexcinctus (Source: JS Ferreira, Brazil).

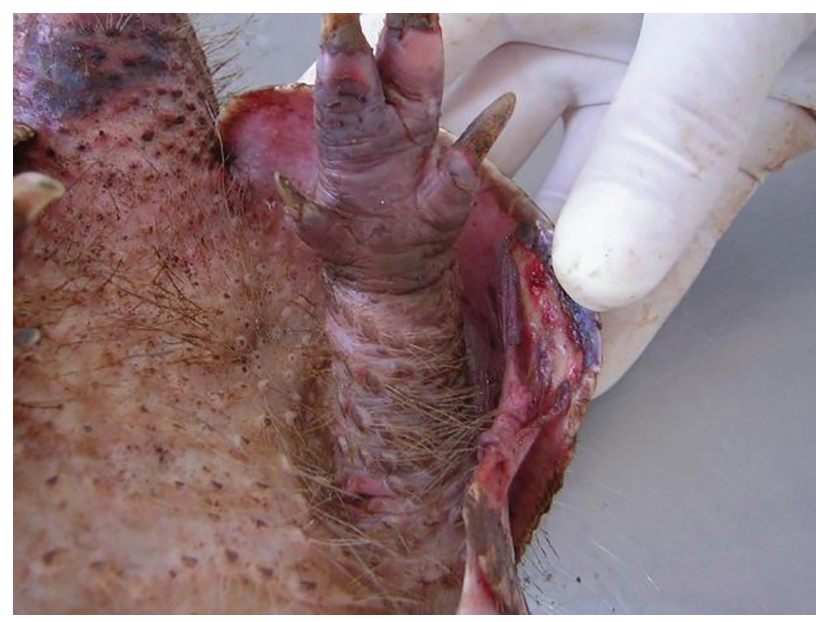

Figure 2 - Injury in a carcass of a naturally infected $D$. novemcinctus (Source: JMAP Antunes, Brazil).

The most important similarity between human and armadillo disease is nerve involvement ${ }^{50,56}$. The unique attributes of the armadillo as an experimental model are the state of controlled and known infection, the duration of disease and the functional similarity with leprosy in humans. Armadillos can also be examined for rare neurological events occurring over time ${ }^{50}$. Histopathological images of armadillo tissues reveal infiltration of macrophages infected with $M$. leprae in the liver, spleen and lymph nodes, and sometimes in lips, tongue, nose, nasal mucosa, skin, bone marrow, eyes, lungs and nerves ${ }^{6}$. Although the interval between infection and developing the disease in experimental infection in armadillos (4 to 24 months) is shorter than in human infection, there is an opportunity to evaluate pathogenesis in preclinical stages that have never been observed in humans ${ }^{50}$.

Perhaps the most critical limitation of the use of armadillos in experiments is the difficulty of the animal reproduction in captivity. Pregnant armadillos, when captured from the wild, provide descendants that may be models for studying the role of host genetics and genomic factors in leprosy susceptibility ${ }^{48}$.

\section{CONCLUSION}

Natural M. leprae infection was first observed in freeliving armadillos of the $D$. novemcinctus species in the USA in $1975^{23}$ and in Brazil in $2002^{29}$. Interest in natural infection in armadillos has increased sharply over the last five years and, in Brazil, we still have much to learn about this disease. E. sexcinctus has become the target of research related to natural leprosy in armadillos, and studies on this zoonosis in Brazil should focus on this species. 


\section{ACKNOWLEDGMENTS}

We thank Dr Simon Collin (National Infection Service, Public Health England, London, UK) for English language revisions to the manuscript.

\section{CONFLICT OF INTERESTS}

The authors state no conflicts of interest.

\section{FUNDING}

No funding has been received for this study.

\section{REFERENCES}

1. Deps PD. Como o Mycobacterium leprae é transmitido? Hansenol Int. 2001;26:31-6.

2. Han XY, Seo YH, Sizer KC, Schoberle T, May GS, Spencer JS, et al. A new mycobacterium species causing diffuse lepromatous leprosy. Am J Clin Pathol. 2008;130:856-64.

3. Benjak A, Avanzi C, Singh P, Loiseau C, Girma S, Busso P, et al. Phylogenetics and antimicrobial resistance of the leprosy bacillus Mycobacterium leprae. Nat Comm. 2018;9:352.

4. Adams LB, Pena MT, Sharma R, Hagge DA, Schurr E, Truman RW. Insights from animal models on the immunogenetics of leprosy: a review. Mem Inst Oswaldo Cruz. 2012;107 Suppl 1:197-208.

5. World Health Organization. Leprosy elimination: what is leprosy? [cited 2019 Aug 8]. Available from: http://who.int/lep/disease/ en/

6. Scollard DM, Adams LB, Gillis TP, Krahenbuhl JL, Truman RW, Williams DL. The continuing challenges of leprosy. Clin Microbiol Rev. 2006;19:338-81.

7. World Health Organization. Leprosy elimination. [cited 2019 Aug 8]. Available from: http://www.who.int/lep/en/

8. World Health Organization. Global Health Observatory (GHO) data: leprosy: situation and trends. [cited 2019 Aug 8]. Available from: https://www.who.int/gho/neglected_diseases/ leprosy/en/

9. Araujo S, Freitas LO, Goulart LR, Goulart IM. Molecular evidence for the aerial route of infection of Mycobacterium leprae and the role of asymptomatic carriers in the persistance of leprosy Clin Infect Dis. 2016;63:1412-20.

10. Deps PD, Antunes JM, Faria C, Bührer-Sékula S, Camargo ZP, Opromola DV, et al. Research regarding anti-PGL-I antibodies by ELISA in wild armadillos from Brazil. Rev Soc Bras Med Trop. 2008;41 Suppl 2:73-6.

11. White C, Franco-Paredes C. Leprosy in the $21^{\text {st }}$ century. Clin Microbiol Rev. 2015;28:80-94.

12. Hamilton HK, Levis WR, Martiniuk F, Cabrera A, Wolf J. The role of the armadillo and sooty mangabey monkey in human leprosy. Int J Dermatol. 2008;47:545-50.

13. Schilling AK, Del-Pozo J, Lurz PW, Stevenson K, Avanzi C, Shuttleworth CM, et al. Leprosy in red squirrels in the UK. Vet Rec. 2019;184:416.

14. Shepard CC. The experimental disease that follows the injection of human leprosy bacilli into foot-pads of mice. J Exp Med. 1960;112:445-54.

15. Kirchheimer WF, Storrs EE. Attempts to establish the armadillo (Dasypus novemcinctus Linn.) as a model for the study of leprosy. I. Report of lepromatoid leprosy in an experimentally infected armadillo. Int J Lepr Other Mycobact Dis. 1971;39:693-702.

16. Storrs EE, Walsh GP, Burchfield HP. Development of leprosy in another species of armadillo, Dasypus hybridus (L): genetic and immunological implications. J Trop Med Hyg. 1975;78:216-8.

17. Balamayooran G, Pena M, Sharma R, Truman RW. The armadillo as an animal model and reservoir host for Mycobacterium leprae. Clin Dermatol. 2015;33:108-15.

18. Honap TP, Pfister LA, Housman G, Mills S, Tarara RP, Suzuki K, et al. Mycobacterium leprae genomes from naturally infected nonhuman primates. PLoS Negl Trop Dis. 2018;12:e006190.

19. Rojas-Espinosa O, Løvik M. Mycobacterium leprae and Mycobacterium lepraemurium infections in domestic and wild animals. Vet Sci Tech. 2001;20:219-51.

20. Truman RW, Singh P, Sharma R, Busso P, Rougemont J, PanizMondolfi A, et al. Probable zoonotic leprosy in the southern United States. N Engl J Med. 2011;364:1626-33.

21. Truman RW, Fine PE. "Environmental” sources of Mycobacterium leprae: issues and evidence. Lepr Rev. 2010;81:89-95.

22. Scollard DM, McCormick G, Allen JL. Localization of Mycobacterium leprae to endothelial cells of epineural and perineural blood vessels and lymphatics. Am J Pathol. 1999;154:1611-20.

23. Walsh GP, Storrs EE, Burchfield HP, Cotrell EH, Vidrine MF, Binford $\mathrm{CH}$. Leprosy-like disease occurring naturally in armadillos. J Reticuloendothel Soc. 1975;18:347-51.

24. Truman R. Leprosy in wild armadillos. Lepr Rev. 2005;76:198208.

25. Amezcua ME, Escobar-Gutiérrez A, Storrs EE, Dhople AM, Burchfield HP. Wild Mexican armadillo with leprosy-like infection. Int J Lepr Other Mycobact dis. 1984;52:254-5.

26. Cardona-Castro N, Beltrán JC, Ortiz-Bernal A, Vissa V. Detection of Mycobacterium leprae DNA in nine-banded armadillos (Dasypus novemcinctus) from the Andean region of Colombia. Lepr Rev. 2009;80:424-31.

27. Cardona-Castro N, Beltrán-Alzate JC, Romero-Montoya IM, Meléndez E, Torres F, Sakamuri RM, et al. Identification and comparison of Mycobacterium leprae genotypes in two geographical regions of Colombia. Lepr Rev. 2009;80:316-21. 
28. Capellão RT, Lazar A, Bonvicino CR. Infecção natural por agentes zoonóticos em tatus (Mammalia: Cingulata) na América do Sul. Bol Soc Bras Mastozool. 2015;73:23-36.

29. Deps PD, Santos AR, Yamashita-Tomimori J. Detection of Mycobacterium leprae DNA by PCR in blood sample from nine-banded armadillo: preliminary results. Int J Lepr Other Mycobact Dis. 2002;70:34-5.

30. Deps PD, Antunes JM, Tomimori-Yamashita J. Detection of Mycobacterium leprae infection in wild nine-banded armadillos (Dasypus novemcinctus) using the rapid ML Flow test. Rev Soc Bras Med Trop. 2007;40:86-7.

31. Antunes JM, Zanini MS, Demoner LC, Deps PD. Diagnosis of Mycobacterium leprae in armadillos (Dasypus novemcinctus) and the correlation with water source proximity in Rive county, Espírito Santo state, Brazil. Vet Zootec. 2009;16:6429.

32. Frota CC, Lima LN, Rocha AS, Suffys PN, Rolim BN, Rodrigues LC, et al. Mycobacterium leprae in six-banded (Euphractus sexcinctus) and nine-banded armadillos (Dasypus novemcinctus) in Northeast Brazil. Mem Inst Oswaldo Cruz. 2012;107 Suppl 1:209-13.

33. Zumarraga MJ, Resoagli EH, Cicuta ME, Martinez AR, Oritiz de Rott MI, de Millan SG, et al. PCR-restriction fragment length polymorphism analysis (PRA) of Mycobacterium leprae from human lepromas and from a natural case of an armadillo of Corrientes, Argentina. Int J Lepr Other Mycobact Dis. 2001;69:21-5.

34. Deps PD, Alves BL, Gripp CG, Aragao RL, Guedes B, Filho JB, et al. Contact with armadillos increases the risk of leprosy in Brazil: a case control study. Indian J Dermatol Venereol Leprol. 2008;74:338-42.

35 Smith JH, Folse DS, Long EG, Christie JD, Crouse DT, Tewes ME, et al. Leprosy in wild armadillos (Dasypus novemcinctus) of the Texas Gulf Coast: epidemiology and mycobacteriology. J Reticuloendothel Soc. 1983;34:75-88.

36. Kerr L, Kendall C, Sousa CA, Frota CC, Graham J, Rodrigues L, et al. Human-armadillo interaction in Ceará, Brazil: potential for transmission of Mycobacterium leprae. Acta Trop. 2015; 152:74-9.

37. Abide JM, Webb RM, Jones HL, Young L. Three indigenous cases of leprosy in the Mississippi delta. South Med J. 2008;101:6358.

38. Clark BM, Murray CK, Horvath LL, Deye GA, Rasnake MS, Longfield RN. Case-control study of armadillo contact and Hansen's disease. Am J Trop Med Hyg. 2008;78:962-7.

39. Truman R. Armadillos as a source of infection for leprosy. South Med J. 2008;101:581-2.

40. Baliña LM, Valdez RP, de Herrera M, Costa Cordova H, Bellocq J, Garcia N. Experimental reproduction of leprosy in sevenbanded armadillos (Dasypus hybridus). Int J Lepr Other Mycobact Dis. 1985;53:595-9.
41. Sharma R, Singh P, Loughry WJ, Lockhart JM, Inman WB, Duthie MS, et al. Zoonotic leprosy in the Southeastern United States. Emerg Infect Dis. 2015;21:2127-34.

42. Monot M, Honoré N, Garnier T, Araoz R, Coppée JY, Lacroix C, et al. On the origin of leprosy. Science. 2005;308:1040-2.

43. da Silva MB, Portela JM, Li W, Jackson M, Gonzalez-Juarrero M, Hidalgo AS, et al. Evidence of zoonotic leprosy in Pará, Brazilian Amazon, and risks associated with human contact or consumption of armadillos. PLoS Negl Trop Dis. 2018;12:e006532.

44. Schmitt JV, Dechandt IT, Dopke G, Ribas ML, Cerci FB, Viesi JM, et al. Armadillo meat intake was not associated with leprosy in a case control study, Curitiba (Brazil). Mem Inst Oswaldo Cruz. 2010;105:857-62.

45. Fontes AN, Sakamuri RM, Baptista IM, Ura S, Moraes MO, Martinez NA, et al. Genetic diversity of Mycobacterium leprae isolates from Brazilian leprosy patients. Lepr Rev. 2009;80:302-15.

46. Perez-Heydrich C, Loughry WJ, Anderson CD, Oli MK. Patterns of Mycobacterium leprae infection in wild nine-banded armadillos (Dasypus novemcinctus) in Mississippi, USA. J Wildl Dis. 2016;52:524-32.

47. Bruce S, Schroeder TL, Ellner K, Rubin H, Williams T, Wolf JE Jr. Armadillo exposure and Hansen's disease: an epidemiologic survey in southern Texas. J Am Acad Dermatol. 2000;43:223-8.

48. Sharma R, Lahiri R, Scollard DM, Pena M, Williams DL, Adams LB, et al. The armadillo: a model for the neuropathy of leprosy and potentially other neurodegenerative diseases. Dis Model Mech. 2013;6:19-24.

49. Antunes SL, Chimelli LM, Rabello ET, Valentim VC, CorteReal S, Sarno EM, et al. An immunohistochemical, clinical and electroneuromyographic correlative study of the neural markers in the neuritic form of leprosy. Braz J Med Biol Res. 2006;39:1071-81.

50. Truman RW, Ebenezer GJ, Pena MT, Sharma R, Balamayooran G, Gillingwater TH, et al. The armadillo as a model for peripheral neuropathy in leprosy. ILAR J. 2014;54:304-14.

51. Blake LA, West BC, Lary CH, Todd JR $4^{\text {th }}$. Environmental nonhuman sources of leprosy. Rev Infect Dis. 1987;9:562-77.

52. Binford CH, Meyers WM, Walsh GP, Storrs EE, Brown HL. Naturally acquired leprosy like disease in the nine-banded armadillo Dasypus novemcinctus, histopathologic and microbiologic studies of tissues. J Reticuloendothel Soc. 1977;22:377-88.

53. Job CK, Drain V, Williams DL, Gillis TP, Truman RW, Sanchez $\mathrm{RM}$, et al. Comparison of polymerase chain reaction technique with other methods for detection of Mycobacterium leprae in tissues of wild nine-banded armadillos. Lepr Rev. 1991;62:36273.

54. Truman R, Sanchez R. Armadillos: models for leprosy. Lab Anim. 1993;22:28-32. 
55. Job CK, Drain V, Truman R, Deming AT, Sanchez RM, Hastings $\mathrm{RC}$. The pathogenesis of leprosy in the nine-banded armadillo and the significance of IgM antibodies to PGL-1. Indian J Lepr. 1992;64:137-51.

56. Scollard DM. Endothelial cells and the pathogenesis of lepromatous neuritis: insights from the armadillo model. Microbes Infect. 2000;2:1835-43.
57. Stallknecht DE, Truman RW, Hugh-Jones ME, Job CK. Surveillance for naturally acquired leprosy in a nine-banded armadillo population. J Wildl Dis. 1987;23:308-10.

58. Truman RW, Job CK, Hastings RC. Antibodies to the phenolic glycolipid-1 antigen for epidemiologic investigations of enzootic leprosy in armadillos (Dasypus novemcinctus). Lepr Rev. 1990;61:19-24.

\section{Erratum}

Page 4, legend of the Figure 1, where it reads:

Figure 1 - Plantar injury in a naturally infected E. sexcinctus (Source: JMAP Antunes, Brazil).

\section{Should be read:}

Figure 1 - Plantar injury in a naturally infected E. sexcinctus (Source: JS Ferreira, Brazil).

Rev Inst Med Trop São Paulo. 2019;61:e44err

http://dx.doi.org/10.1590/s1678-9946201961044err 